ORIGINAL ARTICLE

\title{
CPP-ACP and Fluoride: A Synergism to Combat Caries
}

\author{
Prabhakar Attiguppe ${ }^{1}$, Neetu Malik ${ }^{2}$, Shivani Ballal ${ }^{3}$, Saraswathi V Naik ${ }^{4}$
}

\begin{abstract}
Aims: The aim of this study is to evaluate and compare the demineralization inhibitory effect, fluoride release at varying time intervals, and antibacterial property of $\mathrm{Ml}$ varnish and fluor protector varnish.

Materials and methods: Twenty-four extracted human premolars were sectioned mesiodistally. The buccal and the lingual halves of the teeth were utilized to evaluate the demineralization inhibitory effect and fluoride release of MI varnish and fluor protector varnish, respectively. To evaluate the demineralization inhibitory effect, $150-\mu \mathrm{m}$ axial longitudinal section was obtained that was photographed and evaluated under a polarized light microscope. To evaluate the fluoride release, a fluoride-specific ion electrode was used. To evaluate the antibacterial susceptibility, the disk diffusion test (Kirby-Bauer method) was done.
\end{abstract}

Results: Statistical analysis was done using the Students unpaired $t$ test for intergroup comparison and the $p$ value $<0.01$ was obtained for all the three parameters, i.e., demineralization inhibitory effect, antimicrobial property, and fluoride releasing property at different time intervals. Conclusion: A combination of casein phosphopeptide (CPP)-amorphous calcium phosphate (ACP) in fluoride varnish seems to enhance the caries preventive potential of fluoride varnish and antibacterial activity against Streptococcus mutans.

Clinical significance: MI varnish, a combination of CPP-ACP and fluoride varnish could be the future of minimally invasive dentistry as it is minimally invasive yet an effective modality for caries prevention.

Keywords: Casein phosphopeptide-amorphous calcium phosphate (CPP-ACP), Fluoride, Fluoride varnish, MI varnish.

International Journal of Clinical Pediatric Dentistry (2019): 10.5005/jp-journals-10005-1608

\section{INTRODUCTION}

The modern medical approach to the management of caries is the concept of minimal intervention dentistry which has paved the way for a major shift in the limelight from drill and fill of frank cavitations to evaluating and treating the early precavitation stages, or dealing with the critical risk factors that fuel the vicious carious process. ${ }^{1}$ The essence of this whole new concept of nonoperative treatments has its rationale in new paradigms that focus on minimal invasion and maximum conservation of tooth structure, which is why any restorative treatment must be accompanied by simultaneous disease control at the individual level. ${ }^{2}$

The mainstay of caries prevention revolves around a number of vehicles which have proved themselves to be potent caries inhibiting factors, one of these being fluorides, whose application in various forms, strengthens the enamel structure, making it less susceptible to demineralization by the formation of stronger fluorapatite crystals and enhancing enamel remineralization., 3,4 Although present in low concentrations, the fluoride accumulated in plaque also decreases microbial acid production. Topically applied fluorides buffer $\mathrm{pH}$ of saliva reduces oral cariogenic flora and remineralizes the tooth structure, there by qualitatively altering the saliva. Among various methods of topical application, fluoride varnish which is a concentrated topical fluoride with a resin or synthetic base, is easy to apply, creates less patient discomfort, thereby achieving greater patient acceptability especially in children, and has lesser toxicity than fluoride gel. Also the quantity of fluoride in varnish is less than the gel, thus, reducing the risk of inadvertent ingestion. ${ }^{5}$

However, fluoride as the only agent for caries prevention does not provide a complete solution, since the formation of the fluoride reservoirs and the remineralization potential of saliva is limited by the availability of calcium and phosphate ions. Hence, to enhance the caries-preventing potential of fluoride varnish, calcium and
${ }^{1-4}$ Department of Pedodontics and Preventive Dentistry, Bapuji Dental College and Hospital, Davangere, Karnataka, India

Corresponding Author: Neetu Malik, Department of Pedodontics and Preventive Dentistry, Bapuji Dental College and Hospital, Davangere, Karnataka, India, Phone: +91 9741608625, e-mail: neetumalik89@ gmail.com

How to cite this article: Attiguppe P, Malik N, et al. CPP-ACP and Fluoride: A Synergism to Combat Caries. Int J Clin Pediatr Dent 2019;12(2):120-125.

Source of support: Nil

Conflict of interest: None

phosphate ions have been added in an attempt to increase the retention of both fluoride and calcium ions in the oral environment. ${ }^{6}$

This quest of mankind for novel materials to overcome the carious challenge has led to the introduction of CPP-ACP. ${ }^{7}$ An amorphous form of calcium phosphate (ACP) stabilized by a phosphopeptide from the milk protein casein (CPP) may be used to localize ACP in dental plaque, which buffers free calcium and phosphate ion activity, maintaining a state of supersaturation with respect to tooth enamel that helps prevent demineralization and facilitate remineralization, during acidogenic challenges. ${ }^{8}$ Incorporation of CPP into the salivary pellicle substantially reduces the adhesion of Streptococcus mutans, and this relative selective inhibition would eventually produce a noncariogenic plaque that attributes to its antimicrobial properties. ${ }^{9}$ Hence, recently, more advanced fluoride varnishes with added CPP-ACP have been developed. ${ }^{10}$

However, despite the similar $5 \% \mathrm{NaF}$ concentration used in most of these varnishes, in vitro data have suggested that some of these secondary ingredients can potentially enhance or diminish the fluoride ion release, thereby influencing the anticariogenecity of the product. ${ }^{11,12}$ Therefore, understanding the differences in the 
fluoride release patterns of varnishes with additives like CPP-ACP will help in determining the potential to enhance or diminish the anticariogenicity of the varnish.

\section{Materials and Methods}

The study protocol was approved by the Ethical Committee of Institutional Review Board at Bapuji Dental College and Hospital, Davangere, under the number 434/2015-16. Based on the information available from previous studies, ${ }^{13}$ mean values of experimental and control groups were set at 100 and 93, respectively, with the power of 0.8 . The type I error probability was set at 0.05 to obtain a sample size of 12 per group for all three tested parameters.

\section{Study Groups}

This was an experimental, in vitro intergroup study between two materials, i.e., MI varnish (group MI) and fluor protector varnish (group FP). Block randomized selection was used to allocate the 24 specimens in each group, i.e., group $\mathrm{MI}$ and group FP. The buccal halves, i.e., $B_{1}-B_{24}$, and the lingual halves, i.e., $L_{1}-L_{24}$, of the teeth were utilized to evaluate the demineralization inhibitory effect and fluoride release of $\mathrm{MI}$ varnish and fluor protector varnish, respectively (Flowchart 1 ).

\section{Sample Preparation and Distribution}

Twenty-four sound therapeutically extracted human premolars were used for the study. Teeth with active or initial caries, lesions with hypoplastic areas, large irregularities of enamel surfaces, staining, and developmental defects were excluded. All the teeth were cleaned of their debris with an ultrasonic scaler after which they were stored in $0.1 \%$ thymol solution until the start of the experiment. The teeth were then sectioned using a water-cooled diamond disc in mesiodistal direction, thus, resulting in two specimens, i.e., buccal and lingual halves. Hence, 48 specimens were obtained after sectioning and were stored in distilled water to prevent dehydration. ${ }^{13}$

\section{Sample Preparation for Demineralization Inhibition Potential and Fluoride Release}

Each specimen's surface was then coated with acid resistant nail varnish except for a $5 \mathrm{~mm} \times 1 \mathrm{~mm}$ window in the cervical third, which was delineated using adhesive tape. After removing the adhesive tape, the surfaces were cleaned with a cotton pellet. ${ }^{13}$ Prepared window on the enamel of buccal surfaces $\left(B_{1}-B_{12}\right)$ and lingual surfaces $\left(L_{1}-L_{12}\right)$ was coated with a thin film of MI varnish (GC Corporation) and fluor protector varnish (IvoclarVivadent), respectively, with an applicator as per the instructions from the manufacturer.

\section{Evaluation of Demineralization Inhibitory Effect}

Each specimen was immersed individually in $10 \mathrm{~mL}$ of artificial caries solution containing $2.2 \mathrm{mM} \mathrm{Ca}^{2+}, 2.2 \mathrm{mM} \mathrm{PO}_{4}{ }^{3-}, 50 \mathrm{mM}$ acetic acid, $0.5 \mathrm{ppm} \mathrm{F}$ at a $\mathrm{pH} 4.0$, and $37^{\circ} \mathrm{C}$ for 10 days. After removing from the demineralizing solution, the specimens were rinsed with deionized water. Specimens were mounted on acrylic blocks for sectioning. A $150-\mu \mathrm{m}$ mesiodistal section of the tooth specimens were obtained using a Silverstone-Taylor hard tissue microtome (Leica SP1600), which were then washed with deionized water and oriented longitudinally on glass slides. The sections were evaluated under polarized light microscope (Leica DM 2500 P) and photographed under maximum illumination at $10 \times$ magnification. ${ }^{13}$ The demineralized areas were quantified with a computerized imaging system (Progres Capture Pro 2.88 software) and the mean depth of the lesion was obtained (Figs 1 and 2). ${ }^{14}$

\section{Evaluation of Fluoride Release in Artificial Saliva}

The sectioned samples were then immersed in $30 \mathrm{~mL}$ of prepared artificial saliva and stored at $37^{\circ} \mathrm{C}$ for 30 minutes. At each testing time, the tooth sections were transferred from the $30 \mathrm{~mL}$ of artificial saliva in which they were immersed previously to $30 \mathrm{~mL}$ of fresh artificial saliva. A $5 \mathrm{~mL}$ portion from the previous artificial saliva was used for fluoride testing after 1:1 dilution with total ionic strength adjustment buffer (TISAB) using a fluoride-specific ion electrode connected to a HachSension MM 374 Ion Analyzer (Hach Company, USA), after the first 30 minutes, daily for the first week and then weekly till 1 month. ${ }^{15,16}$

\section{Evaluation of Antimicrobial Property}

Antibacterial susceptibility testing for both the varnishes was done by the disk diffusion test (Kirby-Bauer method). At least, three to five well-isolated colonies of $S$. mutans of the same morphological type were selected from the blood agar plate culture. The top of each colony was touched with a loop, and the growth was transferred into a tube containing $5 \mathrm{~mL}$ of brain heart infusion (BHI) broth. The broth culture was incubated at $37^{\circ} \mathrm{C}$ for 4 hours. Once the actively growing broth culture became turbid, $50 \mu \mathrm{L}$ of the broth was transferred to the middle of a dry $\mathrm{BHI}$ agar and spread uniformly over the entire agar surface using a sterile spreader. ${ }^{17}$ Two wells were prepared on each agar plate using a standard bore of $6 \mathrm{~mm}$ at equal distance from each other. About $10 \mu \mathrm{L}$ of $\mathrm{MI}$ varnish was placed in one well, while $10 \mu \mathrm{L}$ of fluor protector varnish was placed in the other well using a Riviera micropipette. Plates were then incubated anaerobically in a candle extinction jar for 48 hours at $37^{\circ} \mathrm{C}$. The tests were performed in duplicate on $12 \mathrm{BHI}$ agar plates. Antimicrobial property of varnish was assessed by the diameter of circular zones of bacterial inhibition around

Flowchart 1: Specimen distribution

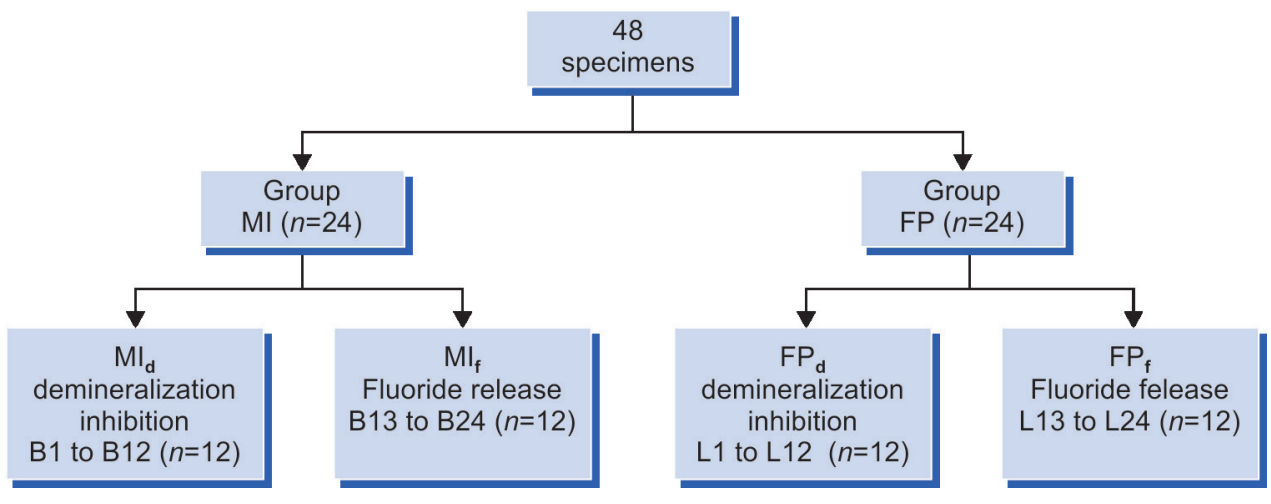




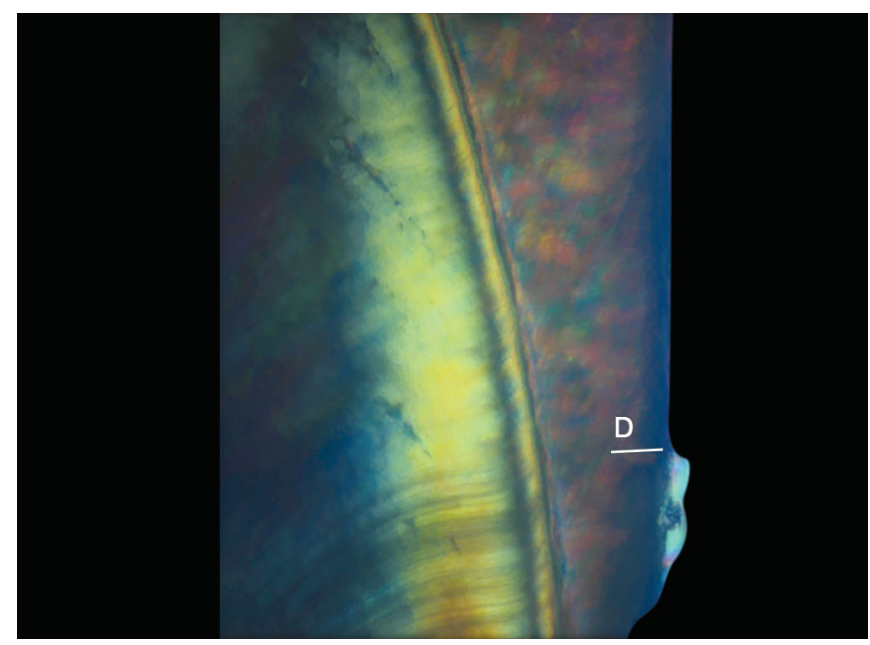

Fig. 1: Demineralization in group $\mathrm{MI}(D=99.18 \mu \mathrm{m})$

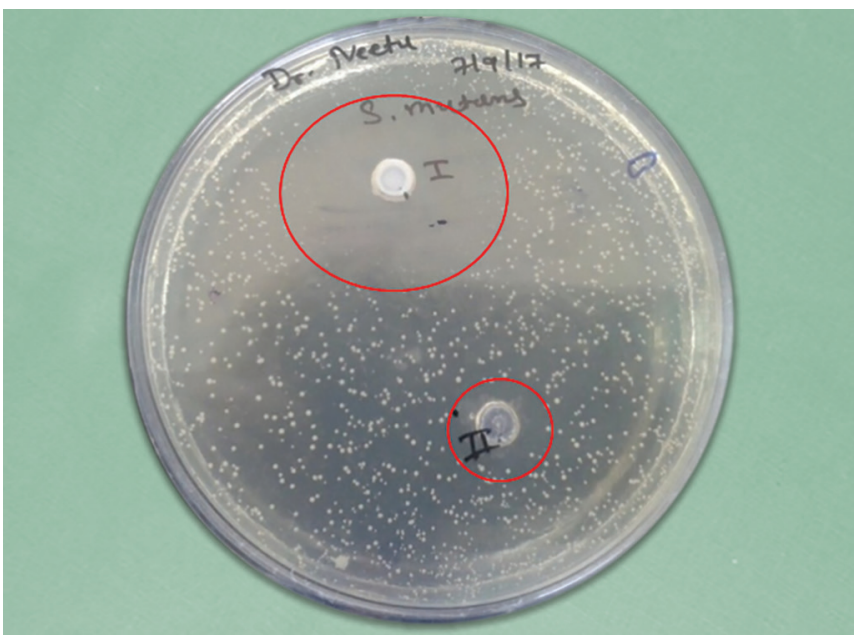

Fig. 3: Zones of bacterial inhibition observed around the wells of the two groups

the wells which were measured in millimeters using a Vernier caliper (Fig. 3). ${ }^{17,18}$

\section{Results}

Results were subjected to appropriate statistical analysis using the Statistical Package for the Social Sciences (SPSS Version 16). Student's unpaired $t$ test was used for an intergroup comparison of demineralization inhibitory effect, antimicrobial property, and fluoride releasing property at different time intervals.

Descriptive statistics showing the mean, standard deviation, and the significance $(p)$ value of difference among the experimental groups with respect to three different parameters is shown in Tables 1 to 4. Group MI showed a greater amount of fluoride release than group FP at all the time intervals. Group MI showed a cumulative fluoride release of $4.19 \pm 0.41 \mathrm{ppm}$, while the group FP showed a cumulative fluoride release of $3.2 \pm 0.19$ ppm after a period of 1 month (Fig.4). Group wise comparison of fluoride release, demineralization inhibitory effect, and antibacterial activity showed a high statistical significant difference among both the groups ( $p$ value $<0.01$ ) (Figs 5 to 7 ).

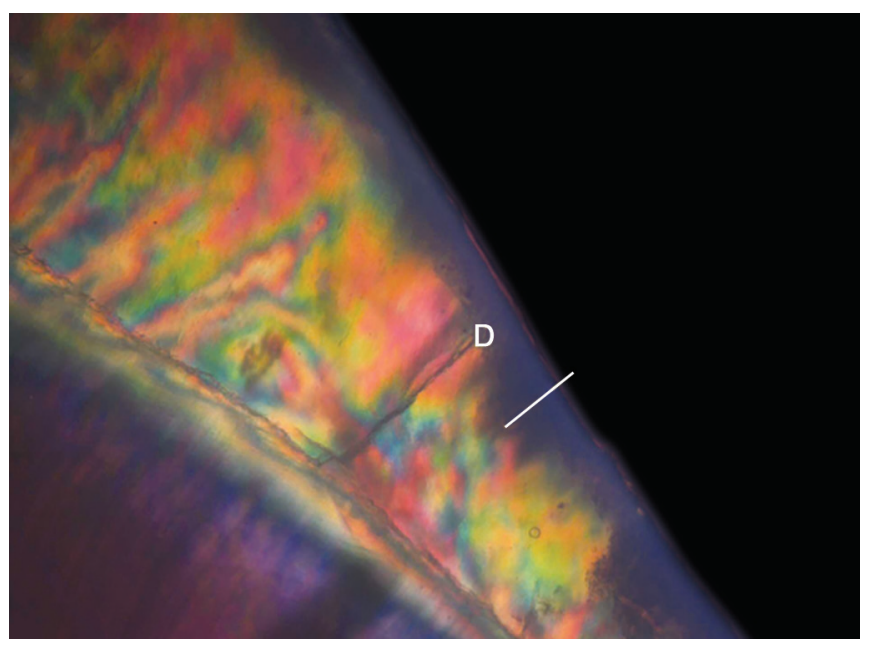

Fig. 2: Demineralization in group FP $(D=119.28 \mu \mathrm{m})$

Table 1: Descriptive statistics showing the mean, standard deviation, and the significance $(p)$ value of difference among the experimental groups with respect to fluoride release at different time intervals

\begin{tabular}{|c|c|c|c|c|}
\hline Time & $\begin{array}{l}\text { Group MI } \\
\text { (mean } \pm S D)\end{array}$ & $\begin{array}{l}\text { Group FP } \\
\text { (mean } \pm S D)\end{array}$ & Tvalue & $p$ value \\
\hline 30 minutes & $0.71 \pm 0.74$ & $0.36 \pm 0.05$ & 13.154 & $<0.0001 *$ \\
\hline Day 1 & $0.63 \pm 0.12$ & $0.37 \pm 0.06$ & 6.217 & $<0.0001 *$ \\
\hline Day 2 & $0.61 \pm 0.18$ & $0.31 \pm 0.06$ & 5.437 & $<0.0001 *$ \\
\hline Day 3 & $0.46 \pm 0.08$ & $0.39 \pm 0.10$ & -1.776 & 0.089 \\
\hline Day 4 & $0.46 \pm 0.17$ & $0.31 \pm 0.05$ & -2.924 & $0.008^{*}$ \\
\hline Day 5 & $0.40 \pm 0.06$ & $0.38 \pm 0.09$ & -0.652 & 0.521 \\
\hline Day 6 & $0.36 \pm 0.04$ & $0.33 \pm 0.10$ & -1.051 & 0.305 \\
\hline Week 2 & $0.32 \pm 0.10$ & $0.277 \pm 0.05$ & 1.221 & 0.235 \\
\hline Week 3 & $0.25 \pm 0.07$ & $0.14 \pm 0.02$ & 4.47 & $<0.0001 *$ \\
\hline Week 4 & $0.22 \pm 0.07$ & $0.09 \pm 0.02$ & 5.89 & $<0.0001 *$ \\
\hline Cumulative & $4.19 \pm 0.41$ & $3.2 \pm 0.19$ & 6.998 & $<0.0001 *$ \\
\hline
\end{tabular}

*Highly significant at $p<0.01$

Table 2: Descriptive statistics showing the mean, standard deviation, and the significance $(p)$ value of difference among the experimental groups with respect to cumulative fluoride release after a period of 1 month

\begin{tabular}{lllll}
\hline Groups & Mean $(p p m)$ & $\begin{array}{l}\text { Standard } \\
\text { deviation }\end{array}$ & Tvalue & p value \\
\hline Group MI & 4.19 & 0.41 & 6.998 & $<\mathbf{0 . 0 0 0 1 *}$ \\
Group FP & 3.2 & 0.19 & & \\
\hline
\end{tabular}

*Highly significant at $p<0.01$

Table 3: Descriptive statistics showing the mean, standard deviation, and the significance $(p)$ value of difference among the experimental groups with respect to demineralization inhibitory effect

\begin{tabular}{lclll}
\hline Groups & Mean $(\mu \mathrm{m})$ & $\begin{array}{l}\text { Standard } \\
\text { deviation }\end{array}$ & Tvalue & p value \\
\hline Group MI & 79.78 & 5.29 & -14.325 & $<\mathbf{0 . 0 0 0 1 *}$ \\
Group FP & 119.2 & 7.92 & & \\
\hline
\end{tabular}

*Highly significant at $p<0.01$ 
Table 4: Descriptive statistics showing the mean, standard deviation, and the significance $(p)$ value of difference among the experimental groups with respect to zone of growth inhibition produced against S. mutans after 48 hours

\begin{tabular}{lllll}
\hline Groups & Mean $(\mathrm{mm})$ & $\begin{array}{l}\text { Standard } \\
\text { deviation }\end{array}$ & Tvalue & pvalue \\
\hline Group MI & 24.75 & 1.76 & -12.017 & $<\mathbf{0 . 0 0 0 1 *}$ \\
Group FP & 15.25 & 2.09 & & \\
\hline
\end{tabular}

*Highly significant at $p<0.01$

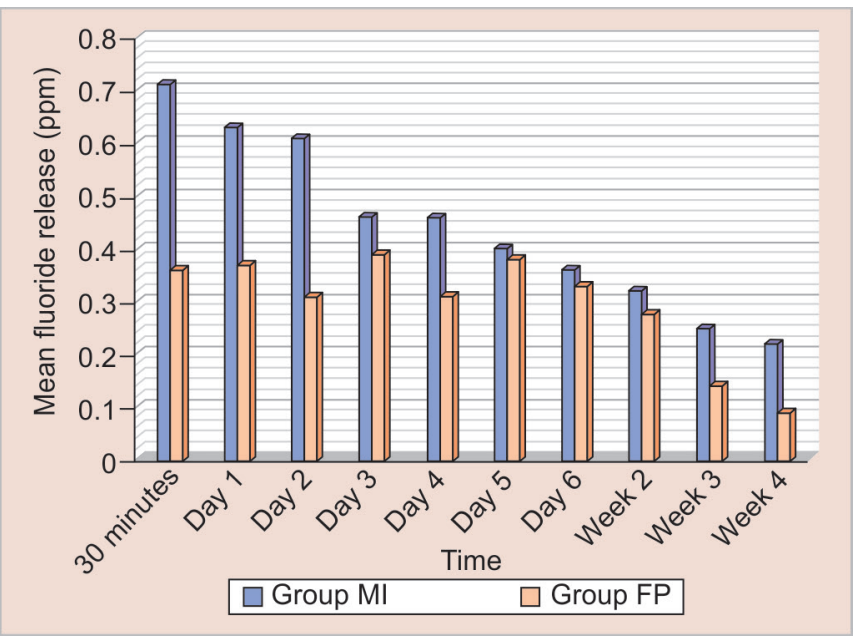

Fig. 4: Intergroup comparison of fluoride release at different time intervals

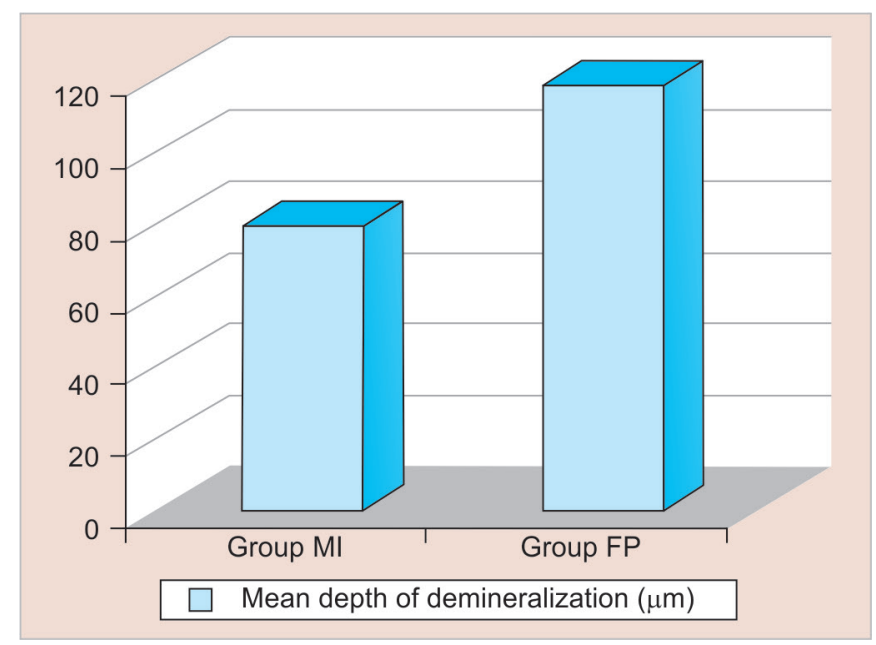

Fig. 6: Intergroup comparison of mean depth of demineralization

\section{Discussion}

Of late, the contemporary dental practice has seen a paradigm shift toward minimal intervention dentistry with respect to diagnosis, preventive strategies, and treatment of dental caries with novel smart materials. ${ }^{19}$ Previous studies have shown that fluoride varnishes have cariostatic properties attributed to the enhancing effect of fluoride on calcium phosphate precipitation, i.e., remineralization. However, enhancing the demineralization inhibition potential of fluoride would lead to a synergistic advantage. ${ }^{20}$

Longbottom et al. in 2009 have shown the importance of calcium and phosphate ions in the remineralization process as they proposed that an ideal caries preventive material should release

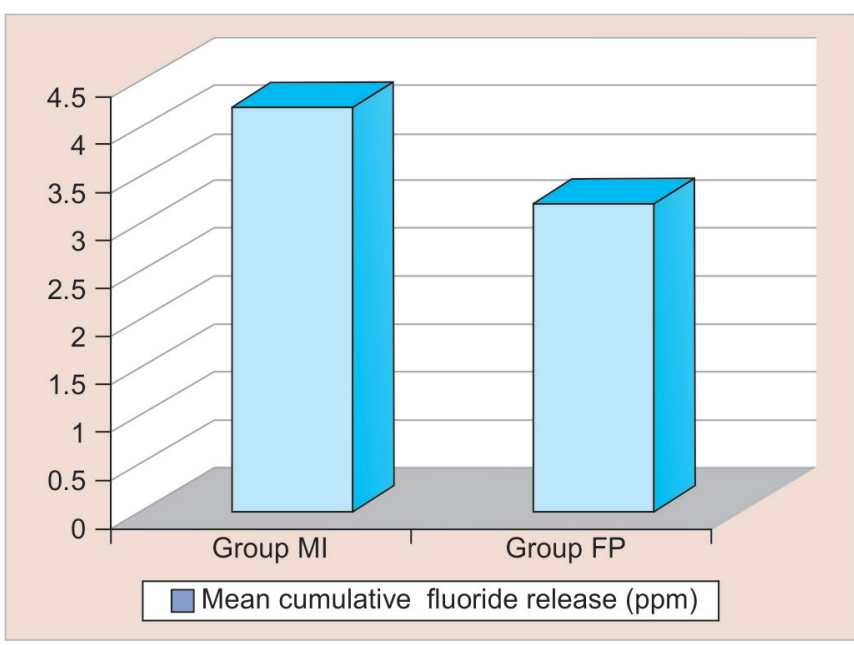

Fig. 5: Intergroup comparison of cumulative fluoride release after a period of 1 month

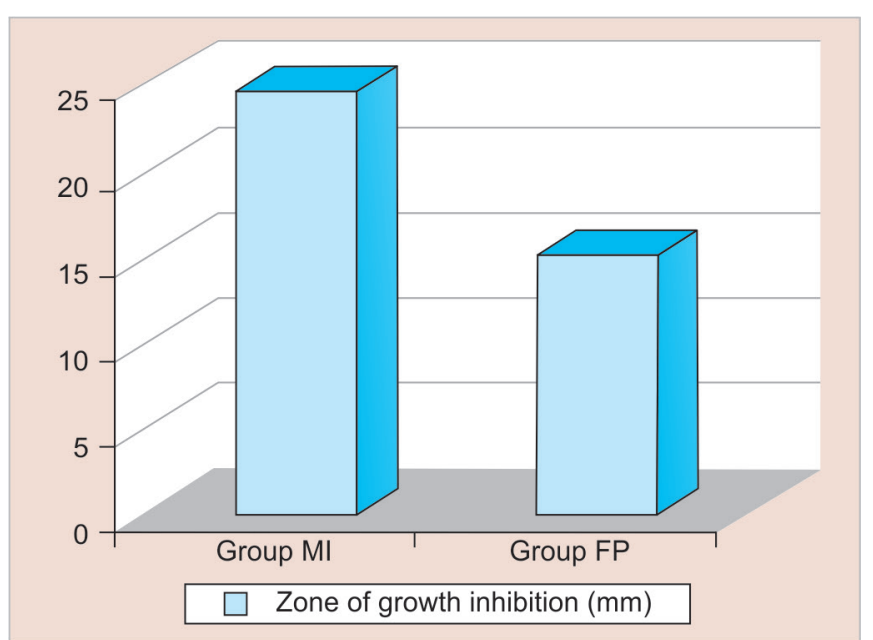

Fig. 7: Intergroup comparison of zones of growth inhibition produced against $S$. mutans after 48 hours

calcium and phosphate in the oral environment. ${ }^{21}$ Therefore, manufacturers of novel caries preventive dental materials are now incorporating CPP-ACP in the composition of their products for the prevention of caries. By virtue of the above strategy, this in vitro study is a modest attempt to explore the influence of incorporation of CPP-ACP in fluoride varnish on demineralization inhibition, salivary fluoride release, and antibacterial properties.

The complexity of the carious process has led to the development of various model systems to improve our understanding of the mechanism of demineralization and remineralization processes. ${ }^{22}$ Such caries model systems also bear a great promise for the eventual determination of the clinical benefits of therapeutic agents in a full-fledged clinical trial. ${ }^{23}$ One such model was used in the present study to showcase the demineralization inhibition potential of the study materials.

The results of our study showed that group MI samples had a lesser mean depth of demineralization than the group FP samples. Such an outcome in our study may be due to the usage of a sodium fluoride varnish with added calcium and phosphates. It has been demonstrated that strongly bound fluoride gets incorporated onto the surface of hydroxyapatite crystals, thus, reducing its solubility and loosely bound fluoride present in the surrounding media 
provides a slow release in the form of ionic fluoride which promotes remineralization. ${ }^{24}$ Also, the addition of calcium and phosphate to fluoride formulations in the form of CPP-ACP can enhance fluoride uptake by enamel. ${ }^{25,26}$

The possible explanation for the lesser mean depth of demineralization observed in group $\mathrm{MI}$ can be attributed to the increased concentration of calcium and phosphate in the saliva as well as subsurface lesions due to CPP-ACP nanoclusters which also buffer the plaque $\mathrm{pH}$ by increasing the calcium and phosphate level in it and, thus, resulting in remineralization process. ${ }^{27}$

The findings of our study were in accordance with a study conducted by Maki Oshiro et al. to demonstrate the remineralizing potential of CPP-ACP on bovine teeth using a scanning electron microscopy (SEM) and it was revealed that the specimens which were treated with CPP-ACP first showed little morphological changes as compared to the remaining specimens which were treated with fluoridated toothpaste. ${ }^{28}$ Christos and George in $2007^{29}$ carried out an in vitro study on human teeth to demonstrate the effect of the CPP-ACP commercial paste on demineralization and remineralization using the multiple internal reflection-Fourier transform infrared spectroscopy (MIR-FTIR) for analysis and concluded that the presence of CPP-ACP agent on dentine caused decreased demineralization and increased remineralization when compared to the dentin surfaces where the CPP-ACP agent was not applied. Similarly, an in vitro study performed by Kumar et al. ${ }^{30}$ where artificial carious lesions were developed in the permanent extracted teeth showed that the percentage depth of demineralization was reduced to $10.1 \%$ when $C P P-A C P$ was used, while it was reduced to 13.2\% upon the use of fluoridated paste.

Also, several in vitro studies have proved the role of CPP-ACP in the reversal of the early white spot lesion. ${ }^{8,31}$ Furthermore, it is shown that CPP-ACP alone or in combination with fluoride can be utilized as a prophylactic agent before the bonding of orthodontic brackets as it inhibits demineralization. ${ }^{32}$

With respect to fluoride ion release of the varnishes, it is important that the addition of calcium and phosphate ions do not reduce the availability of fluoride ions as it is the fluoride that has been shown in clinical trials to provide the caries preventive efficacy of the varnish. ${ }^{11}$ Hence, it was deemed necessary to evaluate the influence of incorporation of CPP-ACP on the fluoride releasing properties of the fluoride varnish.

The ion selective electrode with TISAB III was used for F ion estimation because the $\mathrm{F}$ electrode has tremendous tolerance for extraneous ions like sulfate, phosphate, and organics which invariably interfere with spectrphotometric and fluorometric methods. ${ }^{33}$ Moreover, the amount and duration of $\mathrm{F}$ release also depends upon the test method used, composition of the materials, difference in surface energy, and porosity. ${ }^{34}$ Other critical factors that could influence the results would be the frequency in which the storage solution was renewed, the interval between the changes, and the storage solutions. ${ }^{35}$

In accordance with the above results obtained, Cochrane et al. through an in vitro study showed that, after 168 hours, the cumulative fluoride release from the Bifluorid 5, MI Varnish, Enamel Pro, Duraphat, and Clinpro White was 163, 103, 65, 33, and 20\%, respectively. Overall, the $\mathrm{MI}$ varnish and the enamel pro varnish performed best in terms of fluoride release. The fast release of the ions from Ml varnish under the relatively neutral conditions studied may be attributed to the high water solubility of the CPP-ACP complexes which was validated in the present study. ${ }^{11}$
Streptococcus mutans is established as the leading cause of dental caries worldwide and is considered to be the most cariogenic of the oral Streptococci. It has been implicated most of all as the initiator of dental caries. ${ }^{36,37}$ Since it was impossible to replicate the oral environment with its diverse oral microbiota, the species most commonly implicated in dental caries were chosen in the present study, i.e., Streptococcus mutans.

The agar inhibition tests or disk diffusion method used in our study is in fact an extension of a procedure commonly used in medical laboratories to determine antibiotic sensitivities of bacterial isolates. The result is the identification of potentially effective therapeutic agents and the size of inhibitory zones obtained reveals the microbial sensitivity, agent solubility, and the quantity of agent released within the first few hours after placement. Hence, in this study, this disk diffusion method was chosen because it can be performed rapidly and easily with a large numbers of specimens and is relatively inexpensive. ${ }^{38}$ In this study, the experimental materials were assessed for their antibacterial activity after 48 hours by measuring the inhibition zones produced against $S$. mutans which was significantly greater for group MI than the group FP.

Analyzing all the three parameters tested in this study, it can be stated that the addition of CPP-ACP conferred demineralization inhibitory effect to the conventional fluoride varnish. It may be drawn that fluoride release alone from the conventional fluoride varnish may not be sufficient to cause an antibacterial effect against cariogenic organism and prevent subsurface demineralization. Also, the addition of CPP-ACP increased the fluoride release from the fluoride varnish which might have further enhanced its remineralization property.

\section{Conclusion}

- Combination of CPP-ACP in fluoride varnish seems to enhance the caries preventive potential of fluoride varnish by inhibition of demineralization and antibacterial activity against S. mutans.

- The ion release profile of Ml carnish is a very promising asset as it has a high fluoride releasing potential which makes it an effective approach for caries prevention.

\section{Clinical Significance}

Ml varnish, a combination of CPP-ACP and fluoride varnish, could be the future of minimally invasive dentistry as it is minimally invasive yet an effective modality for caries prevention.

\section{References}

1. Walsh LJ, Brostek AM. Minimum intervention dentistry principles and objectives. Aust Dent J 2013 Jun;58(Suppl 1):3-16. DOI: 10.1111/ adj.12045.

2. Fejerskov O. Changing paradigms in concepts on dental caries: consequences for oral health care. Caries Res 2004 May-Jun;38(3): 182-191. DOI: 10.1159/000077753.

3. Dholam KP, Somani PP, et al. Effectiveness of Fluoride Varnish Application as Cariostatic and Desensitizing Agent in Irradiated Head and Neck Cancer Patients. Int J Dent 2013;2013:824982. DOI: $10.1155 / 2013 / 824982$.

4. Kohn WG, Maas WR, et al. Recommendations for using fluoride to prevent and control dental caries in the United States. Centers for Disease Control and Prevention. MMWR Recommendations and reports: morbidity and mortality weekly report. Recommendations and reports/Centers for Disease Control. 2001;50(RR-14):1. 
5. American Dental Association Council on Scientific Affairs. Professionally applied topical fluoride: Evidence-based clinical recommendations. J Am Dent Assoc 2006 Aug 31;137(8):1151-1159. DOI: 10.14219/jada.archive.2006.0356.

6. Santos Lde M, Reis Jl, et al. In vitro evaluation of fluoride products in the development of carious lesions in deciduous teeth. Braz Oral Res 2009;23:296-301. DOI: 10.1590/S1806-83242009000300012.

7. Kalra DD, Kalra RD, et al. Nonfluorideremineralization. An evidencebased review of contemporary technologies. J Dent Allied Sci 2014;3:24-33. DOI: 10.4103/2277-4696.156525.

8. Reynolds EC. Remineralization of Enamel Subsurface lesions by Casein Phosphopeptide-stabilized Calcium Phosphate Solutions. J Dent Res 1997;76:1587-1589. DOI: 10.1177/00220345970760091101.

9. Schüpbach P, Neeser JR, et al. Incorporation of caseinoglycomacropeptide and caseinophosphopeptide into the salivary pellicle inhibits adherence of mutans streptococci. J Dent Res 1996 Oct;75(10):1779-1788. DOI: 10.1177/00220345960750101101.

10. Wagner JA, Kawamoto AT. Inventors; Ultradent Products, Inc., assignee. Fluoride varnish compositions including an organo phosphoric acid adhesion promoting agent. United States patent US 8,383,163. 2013 Feb 26.

11. Cochrane NJ, Shen $P$, et al. Ion release from calcium and fluoride containing dental varnishes. Aust Dent J 2014 Mar;59(1):100-105. DOI: 10.1111/adj.12144.

12. Cochrane NJ, Cai F, et al. New approaches to enhanced remineralization of tooth enamel. J Dent Res 2010;89:1187-1197. DOI: $10.1177 / 0022034510376046$.

13. Duraisamy $V$, Xavier $A$, et al. An in vitro evaluation of the demineralization inhibitory effect of $\mathrm{F}^{-}$varnish and casein phosphopeptide-amorphous calcium phosphate on enamel in young permanent teeth. J Pharm Bioall Sci 2015;7:S513-S517. DOI: 10.4103/0975-7406.163521.

14. Prabhakar AR, Manojkumar AJ, et al. In vitro remineralization of enamel subsurface lesions and assessment of dentine tubule occlusion from $\mathrm{NaF}$ dentifrices with and without calcium. J Indian Soc Pedod Prev Dent 2013 Jan-Mar;31(1):29-35. DOI: 10.4103/0970-4388.112403.

15. Oncag G, Tuncer AV, et al. Acidic soft drinks effects on the shear bond strength of orthodontic brackets and a scanning electron microscopy evaluation of the enamel. Angle Orthod 2005 Mar;75(2):247-253.

16. Jablonowski BL, Bartoloni JA, et al. Fluoride release from newly marketed fluoride varnishes. Quintessence Intl 2012 Mar 1;43(3):221-228.

17. Arul SK, Rajendra SC, et al. Antibacterial activity of bee propolis against clinical strains of Streptococcus mutans \& synergism with chlorhexidine. Int J Pharm Sci Res 2011 Jan-Mar;2(1):85-90.

18. Kumar MM, Pai BH, et al. Antibacterial properties of fluoride releasing glass ionomer cement \& pit \& fissure sealants on Streptococcus mutans. Int J Clin Pediatr Dent 2010 May-Aug;3(2):93-96. DOI: 10.5005/jp-journals-10005-1060.

19. Stewart RE, Hale KJ. The paradigm shift in the etiology, prevention, and management of dental caries: its effect on the practice of clinical dentistry. J Calif Dent Assoc 2003 Mar;31(3):247-251.

20. Schemehorn BR, Wood GD, et al. Comparison of fluoride uptake into tooth enamel from two fluoride varnishes containing different calcium phosphate sources. J Clin Dent 2011;22(2):51-54.
21. Longbottom C, Ekstrand K, et al. Novel preventive treatment options. Monogr Oral Sci 2009;21:156-163.

22. Proskin HM. Statistical considerations related to the use of caries model systems for the determination of clinical effectiveness of therapeutic agents. Adv Dent Res 1995 Nov;9(3):270-278. DOI: 10.1177/08959374950090031101.

23. Theuns HM, Van Dijk JWE, et al. Effect of time and degree of saturation of buffer solutions on artificial carious lesion formation in human tooth enamel. Caries Res 1983;17(6):503-521. DOI: 10.1159/000260710.

24. Featherstone JDB. Prevention and reversal of dental caries: role of low level fluoride. Community Dent Oral Epidemiol 1999 Feb;27(1):31-40. DOI: 10.1111/j.1600-0528.1999.tb01989.x.

25. Hong YC, Chow LC, et al. Enhanced fluoride uptake from mouth rinses. JDent Res 1985 Feb;64(2):82-84.DOI: 10.1177/00220345850640021401.

26. Chow LC, Guo MK, et al. Apatitic Fluoride increase in enamel from a topical treatment involving intermediate $\mathrm{CaHPO}_{4} \cdot 2 \mathrm{H}_{2} \mathrm{O}$ formation, an in vivo study. Caries Res 1981;15(5):369-376. DOI: 10.1159/000260540.

27. Wilson N. Minimally invasive dentistry-the management of dental caries. London: Quintessence; 2007. pp. 69-70.

28. Oshiro M, Yamaguchi K, et al. Effect of CPP-ACP paste on tooth mineralization: an FE-SEM study. J Oral Sci 2007 Jun;49(2):115-120. DOI: 10.2334/josnusd.49.115.

29. Rahiotis C, Vougiouklakis G. Effect of a CPP-ACP agent on the demineralization and remineralization of dentine in vitro. J Dent 2007 Aug;35(8):695-698. DOI: 10.1016/j.jdent.2007.05.008.

30. Kumar VL, Itthagarun A, et al. The effect of casein phosphopeptideamorphous calcium phosphate on remineralization of artificial carieslike lesions: an in vitro study. Aust Dent J 2008 Mar;53(1):34-40. DOI: 10.1111/j.1834-7819.2007.00006.x.

31. Shen $P, C a i F$, et al. Remineralization of enamel subsurface lesions by sugar-free chewing gum containing casein phosphopeptideamorphous calcium phosphate. J Dent Res 2001 Dec;80(12):2066-2070. DOI: 10.1177/00220345010800120801.

32. Tabrizi A, Cakirer B. A comparative evaluation of casein phosphopeptide-amorphous calcium phosphate and fluoride on the shear bond strength of orthodontic brackets. Eur J Orthod 2011 Jun;33(3):282-287. DOI: 10.1093/ejo/cjq062.

33. Ekstrand J, Burt BA, et al. Fluorides in dentistry, 2nd ed. Copenhagen: Munksgaard; 1996.

34. Hatibovic-Kofman S, Koch G, et al. Glass ionomer materials as a rechargeable fluoride-release system. Int J Paediatr Dent 1997 Jun;7(2):65-73. DOI: 10.1111/j.1365-263X.1997.tb00281.x.

35 Carvalho AS, Cury JA. Fluoride release from some dental materials in different solutions. Oper Dent 1999 Jan-Feb;24(1):14-19.

36. Ajdić $D$, et al. Genome sequence of Streptococcus mutans UA159, a cariogenic dental pathogen. Proc Natl Acad Sci U S A 2002 Oct 29;99(22):14434-14439. DOI: 10.1073/pnas.172501299.

37. Tanzer JM, Livingston J, et al. The microbiology of primary dental caries in humans. J Dent Educ 2001 Oct;65(10):1028-1037.

38. Vermeersch G, Leloup G, et al. Antibacterial activity of glass-ionomer cements, compomers and resin composites: relationship between acidity and material setting phase. J Oral Rehabil 2005 May;32(5): 368-374. DOI: 10.1111/j.1365-2842.2004.01300.x. 